\title{
Corrigendum: Identification and Characterization of miRNAs in Response to Leishmania donovani Infection: Delineation of Their Roles in Macrophage Dysfunction
}

\author{
Neeraj Tiwari ${ }^{1+}$, Vinod Kumar ${ }^{2 \dagger}$, Mallikarjuna Rao Gedda ${ }^{1}$, Ashish K. Singh ${ }^{1}$, \\ Vijay K. Singh ${ }^{3}$, Surya P. Singh ${ }^{1}$ and Rakesh K. Singh ${ }^{1 *}$ \\ ${ }^{1}$ Molecular Immunology Group, Department of Biochemistry, Institute of Science, Banaras Hindu University, Varanasi, India, \\ ${ }^{2}$ Department of Parasitology and Molecular Biology, Rajendra Memorial Research Institute, Patna, India, ${ }^{3}$ Bioinformatics \\ Programme, Centre for Biological Science, Central University of South Bihar, Patna, India
}

Keywords: L. donovani, miRNA, biomarkers, macrophages, dysfunction

\section{A corrigendum on}

\section{OPEN ACCESS}

Edited and reviewed by: Thomas Dandekar, University of Würzburg, Germany

*Correspondence:

Rakesh K. Singh rakesh_bc@bhu.ac.in

${ }^{\dagger}$ These authors have contributed equally to this work.

Specialty section: This article was submitted to Infectious Diseases,

a section of the journal

Frontiers in Microbiology

Received: 27 April 2017

Accepted: 12 June 2017

Published: 27 June 2017

Citation:

Tiwari N, Kumar V, Gedda MR, Singh AK, Singh VK, Singh SP and

Singh RK (2017) Corrigendum: Identification and Characterization of miRNAs in Response to Leishmania donovani Infection: Delineation of

Their Roles in Macrophage

Dysfunction. Front. Microbiol. 8:1190.

doi: 10.3389/fmicb.2017.01190
Identification and Characterization of miRNAs in Response to Leishmania donovani Infection: Delineation of Their Roles in Macrophage Dysfunction

by Tiwari, N., Kumar, V., Gedda, M. R., Singh, A. K., Singh, V. K., Singh, S. P., et al. (2017). Front. Microbiol. 8:314. doi: 10.3389/fmicb.2017.00314

It has come to our attention that Dr. Sreenivas Gannavaram does not meet criteria necessary to be listed as an author, as specified by Frontiers; therefore, he has been removed from the authors' list and mentioned Acknowledgments instead.

The updated Author Contributions statement and Acknowledgments are below.

The authors apologize for this error and state that it does not change the scientific conclusions of the article in any way.

The original article has been updated.

\section{AUTHOR CONTRIBUTIONS}

NT, VK, MG, and AS: designed and performed the experiments and co-wrote the MS. SS and VS: assisted in design of the study, statistical analysis, and MS writing. RS: conceived, designed, directed, and supervised the complete study.

\section{ACKNOWLEDGMENTS}

Financial support from Department of Science and Technology, New Delhi (SB/SO/HS/0091/2013) is greatly acknowledged. NT and MG are thankful to University Grants Commission (UGC) \& BHU for their research fellowships and VK is thankful to DST (YSS/2015/000687) for providing fellowship. The technical support received from V. K. Singh, Bioinformatics Centre, School of Biotechnology, Banaras Hindu University is greatly acknowledged. We thank Dr. Sreenivas 
Gannavaram, CBER, Food and Drug Administration, USA for his valuable suggestions.

Conflict of Interest Statement: The authors declare that the research was conducted in the absence of any commercial or financial relationships that could be construed as a potential conflict of interest.
Copyright (c) 2017 Tiwari, Kumar, Gedda, Singh, Singh, Singh and Singh. This is an open-access article distributed under the terms of the Creative Commons Attribution License (CC BY). The use, distribution or reproduction in other forums is permitted, provided the original author(s) or licensor are credited and that the original publication in this journal is cited, in accordance with accepted academic practice. No use, distribution or reproduction is permitted which does not comply with these terms. 